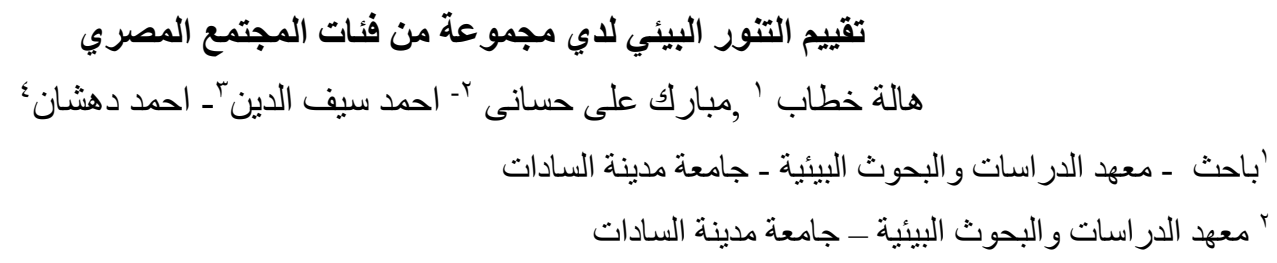

الملخص

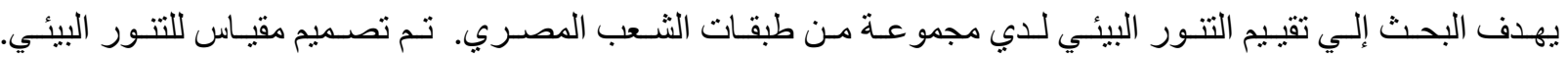

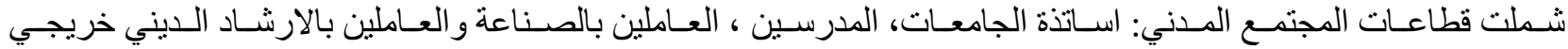

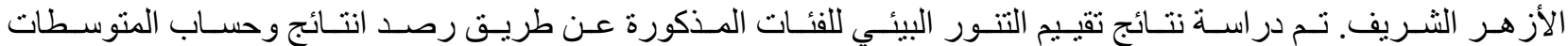

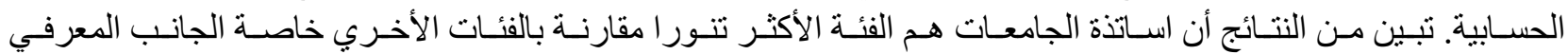

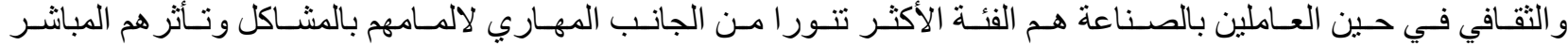

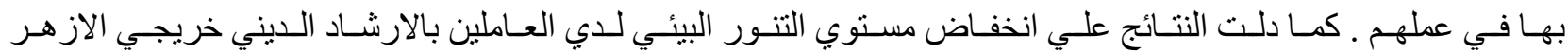

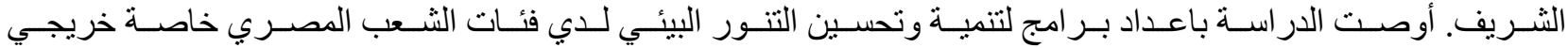
الأزهر و العاملين بالارشاد الديني لقوة تأثير هم المباتشر بالمو اطنين في الو عظو الإرشاد.

كلمات داله:بيئة المجتمع المصرى

\title{
Abstract:
}

This study aims to evaluate the environmental literacy of different sectors from Egyptian society. Environmental literacy measure is designed. The sectors are university professors, teachers, industrial workers and AlAzhar graduated. The answers of environmental literacy measure are studied with reference to arithmetic mean. The results are discussed. The university professors are the best environmental literate. The study recommended preparing programs for development environmental literacy for AlAzhar graduated. .

Key worde: environment, literacy, Egyptian society.

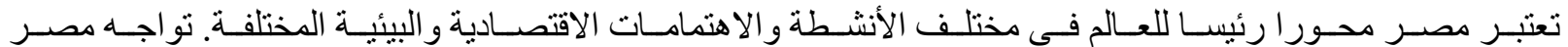

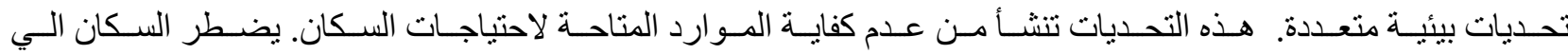

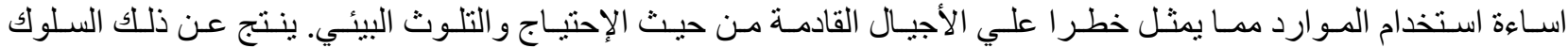

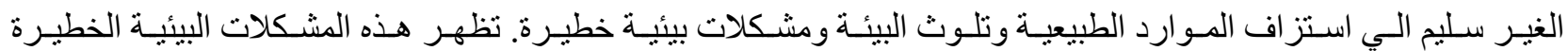

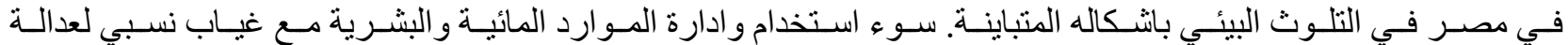

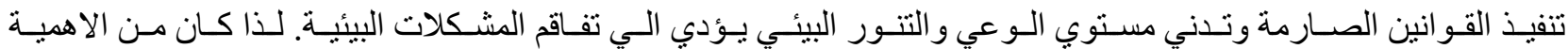

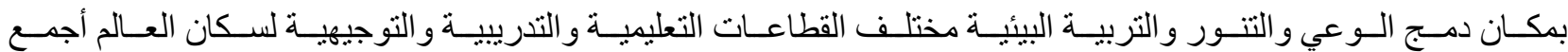

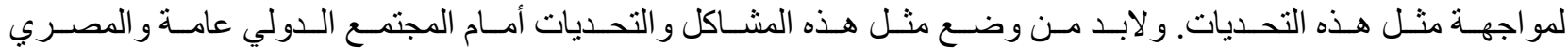

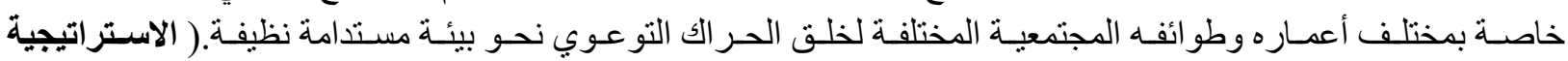

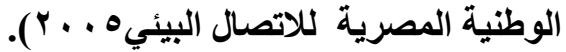

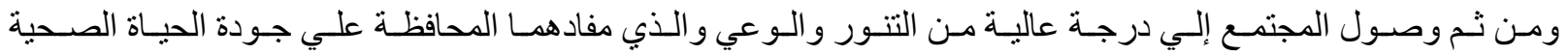

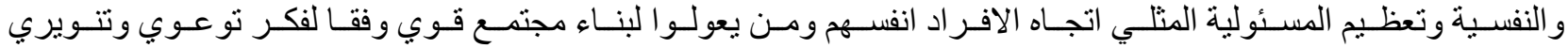

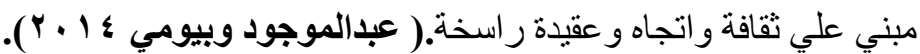




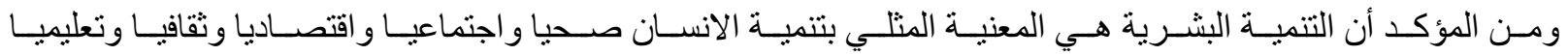

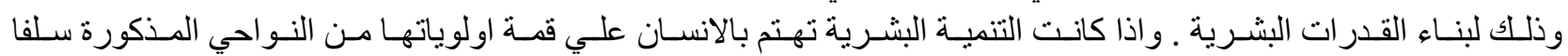

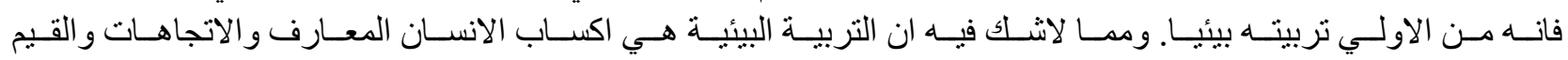

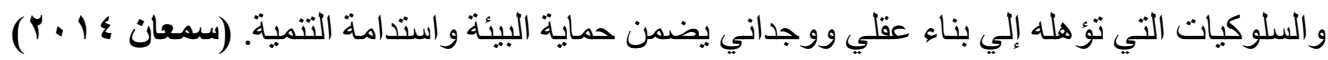

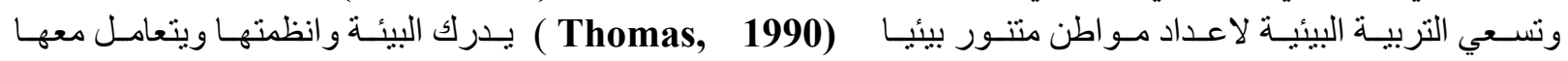

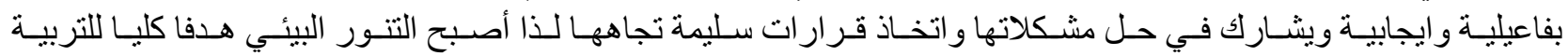

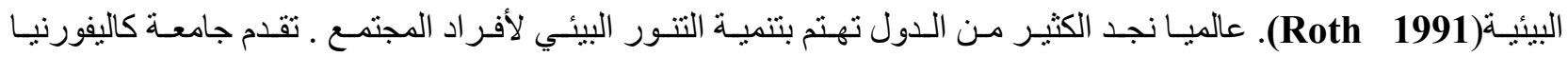
(California)

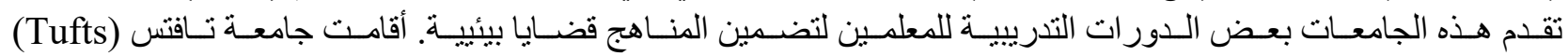

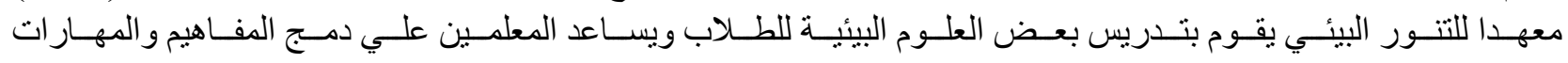
و السلوكيات البيئية في المناهج التعليمية.

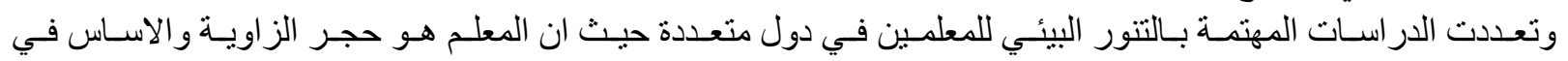

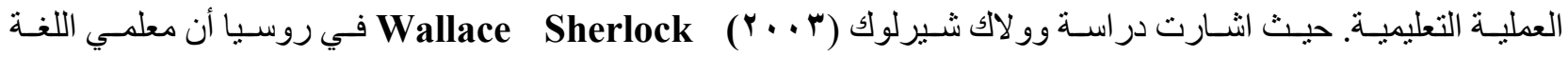

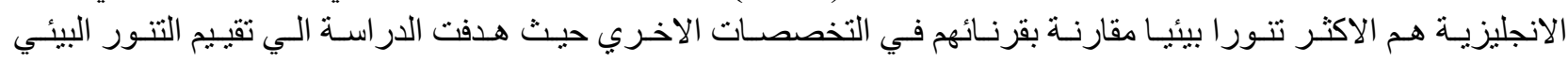
ومعرفة اثر الثقافات المختلفة عليه.

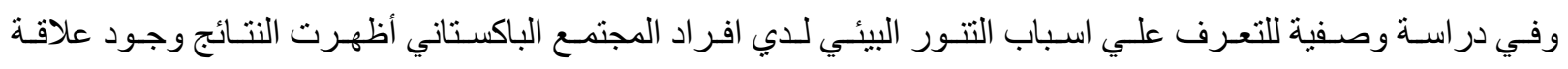

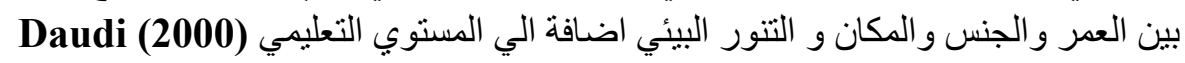

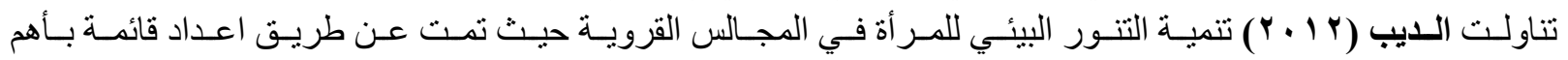

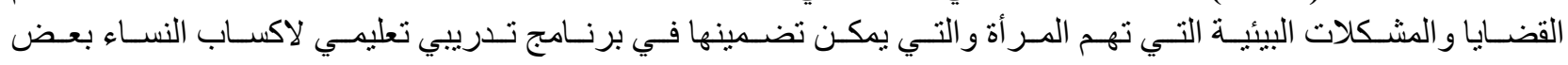

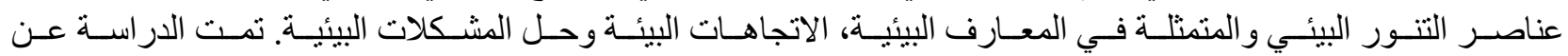

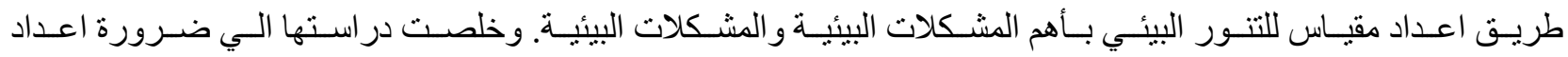

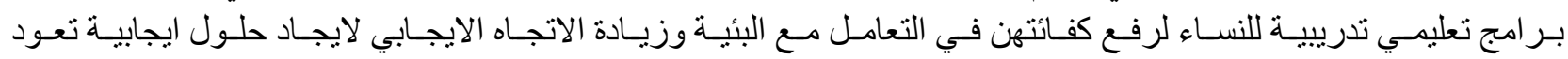
بالنفع علي المجتمع.

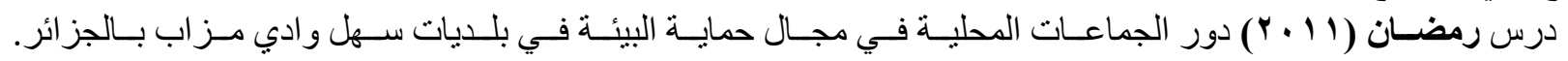

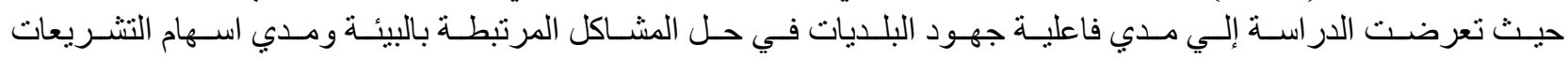

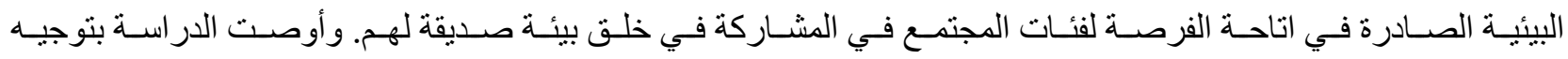

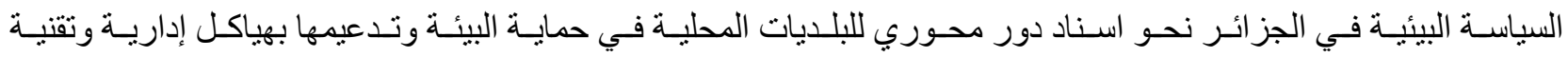

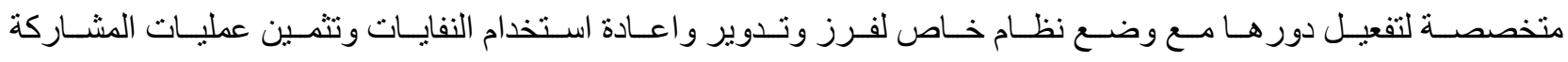

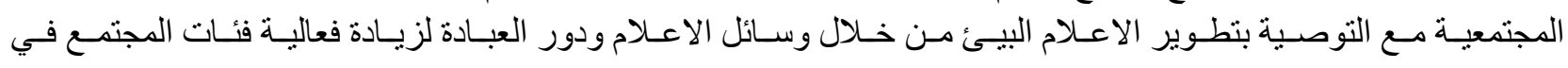

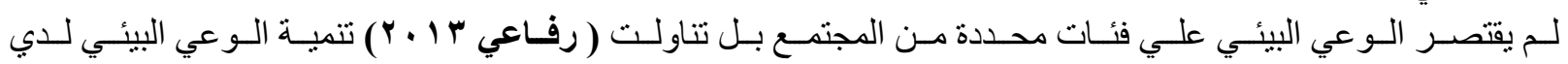

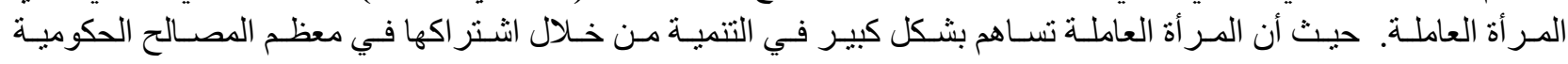

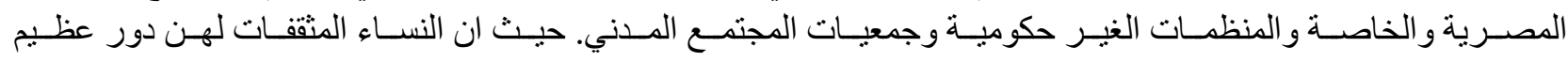

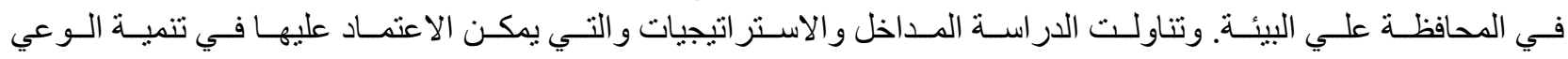

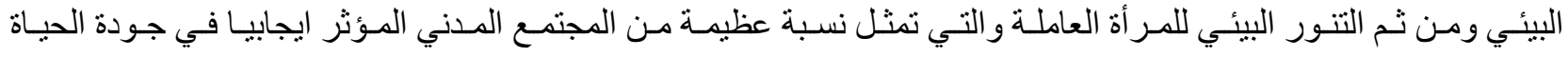

بمشتملاتها.

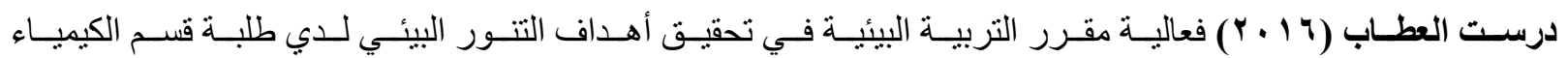

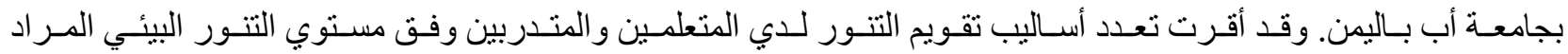

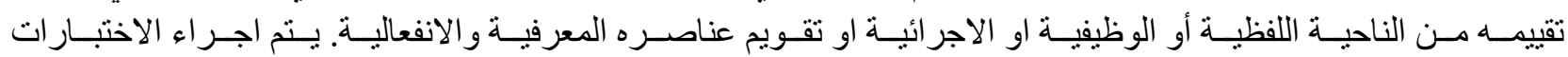

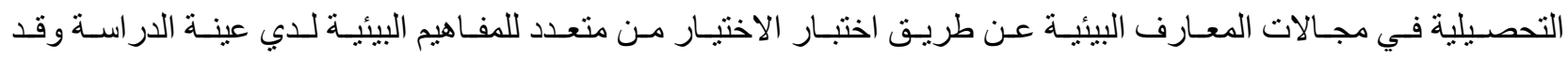

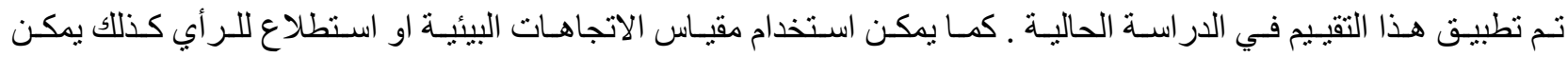
تقييم محتوي الكتب المدرسية من المفاهيم البيئية . 
ويتضح من مر اجعة الدرسات السابقة ما يلي:

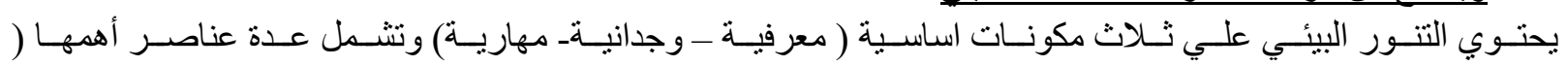

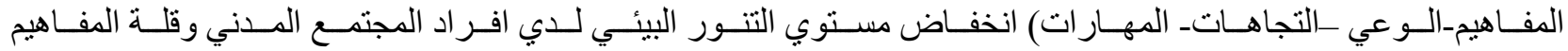

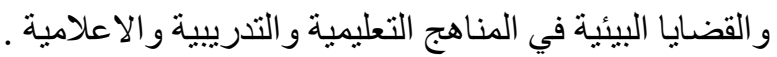

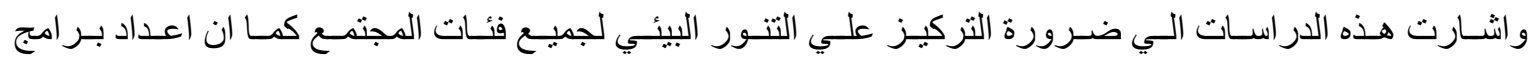
بيئية في كل المناحي التعليمية والاعلامية يساعد بالضرورة علي تتمية وتحسين التنور البيئي.

أسئلة الار اسةة:

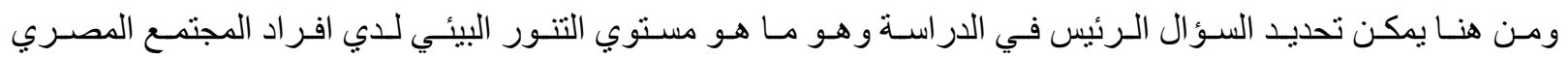

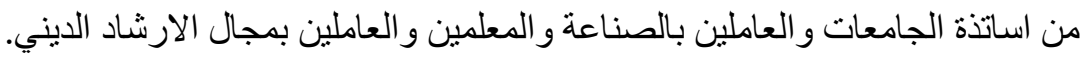

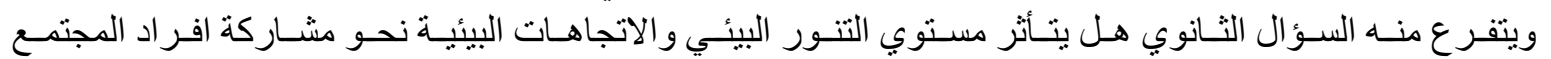
في القضايا البيئية بالمستوي التعليمي والخبرة في مجالات الحياة؟ هل

أهداف الدراسة:

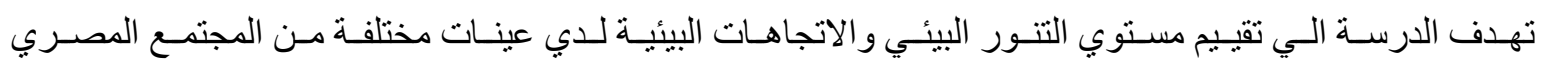
و المتمثلة في اساتذة الجامعات و العاملين بالصناعة والتعليم والارشاد الديني.

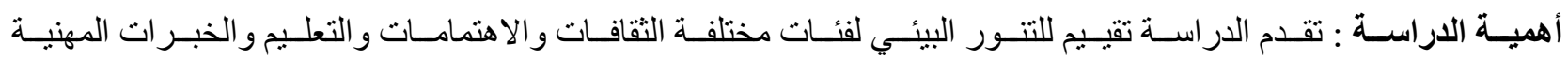

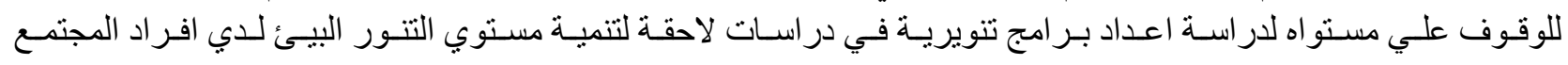
المصري. حدود الاراسة :

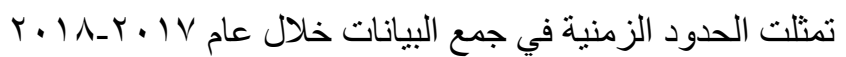

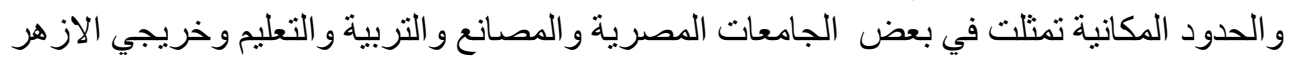

\section{مصطلحات الاراسة:}

\section{Environmental literacy التنور البيئي}

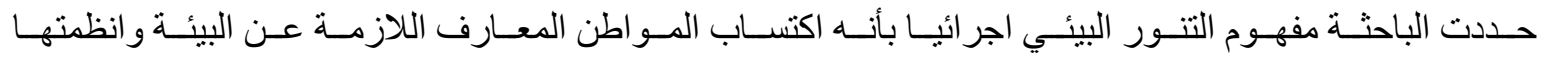

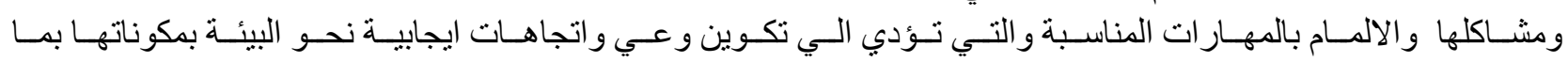

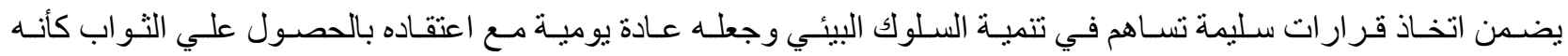
عبادة. المجتمع المصري: يشمل فئات مختلفة الثقافات و الدرجات العلمية و المهنية من افر اد المجتمع.

خطوات الاراسة:

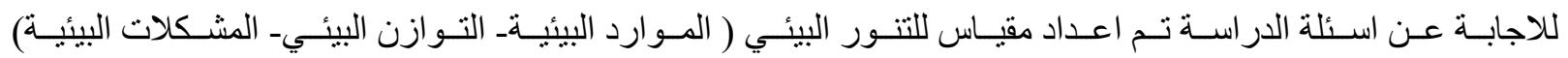

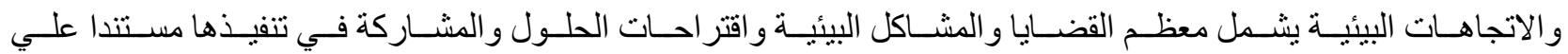

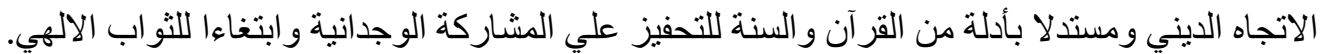

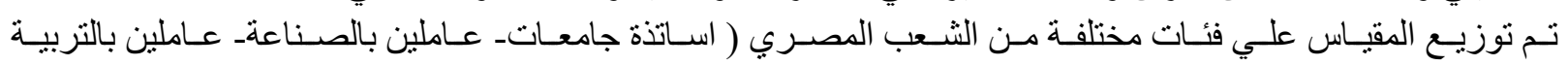

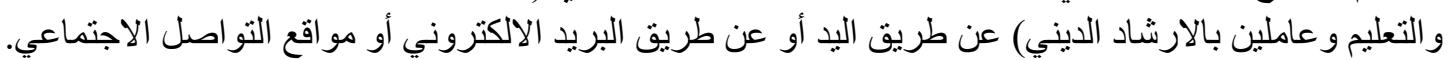

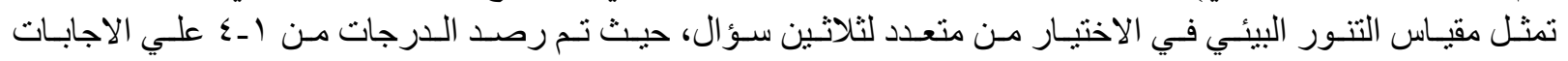

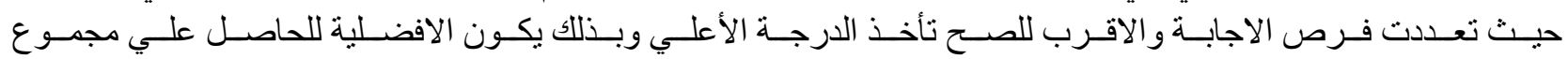

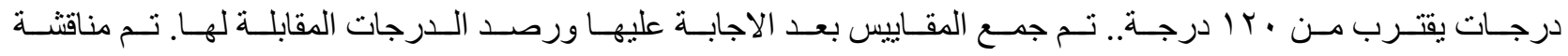

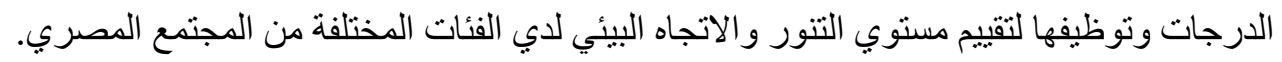




\section{نتائج الاراسة ومناقثتها:}

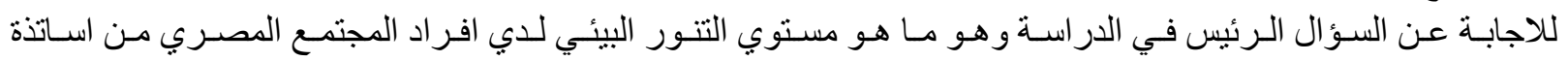

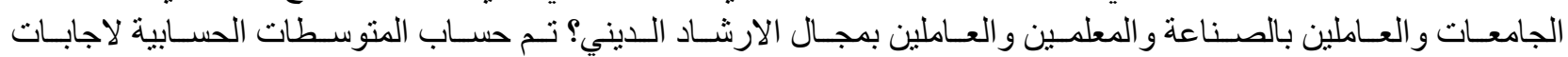

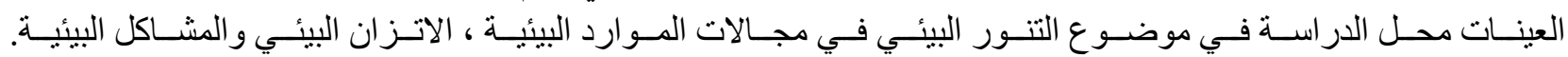

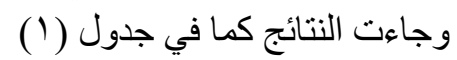
جدول(1) المتوسطات الحسابية لارجات مقياس التنور البيئي لفئات مختلفة من المجتمع المصري.

\begin{tabular}{|c|c|c|c|}
\hline المشاكل البيئية & الاتزان البيئي & الموارد البيئية & الفئة \\
\hline$r q, V T$ & r & $\Gamma \wedge, T \Gamma$ & اساتذة الجامعات \\
\hline דו, & 47,19 & $r_{0, q}$ & العــــــاملين بالتربيـــــــة \\
\hline & & & والتعليم \\
\hline$r V, I V$ & ro, ru & Tr & العاملين بالصناعة \\
\hline I & $T, Y V$ & r. & 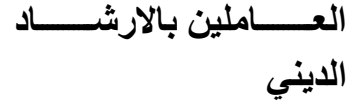 \\
\hline
\end{tabular}

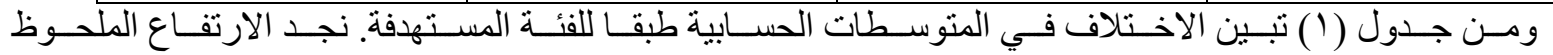

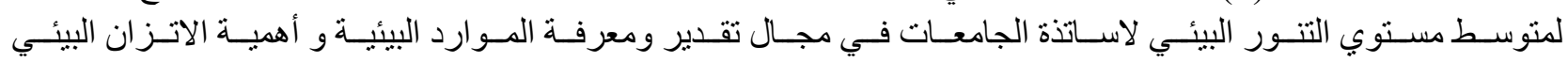

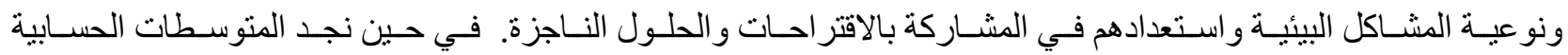

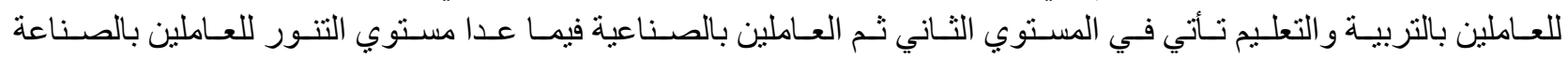

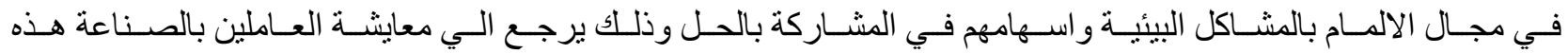

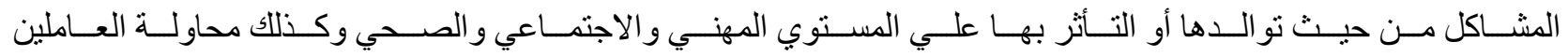

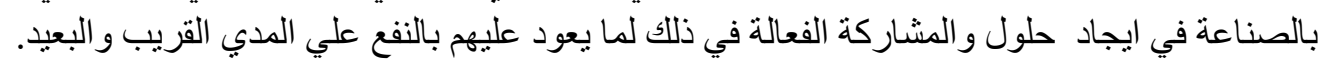

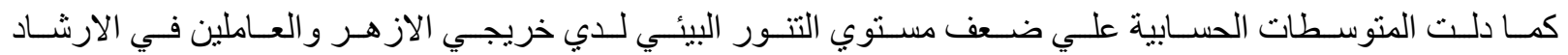

الديني في مجالات الدراسة الثلاثة وهي الموارد البيئية والاتزان البئية البيئي و المشاكل البيئية.

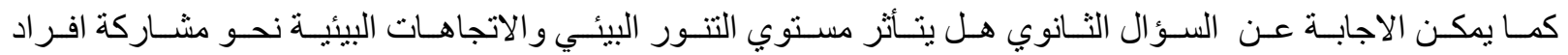

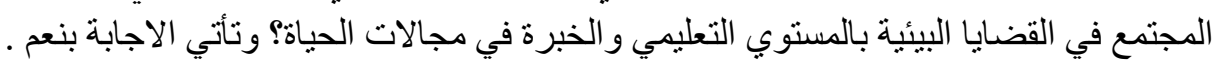

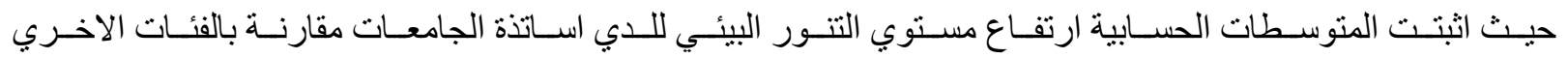

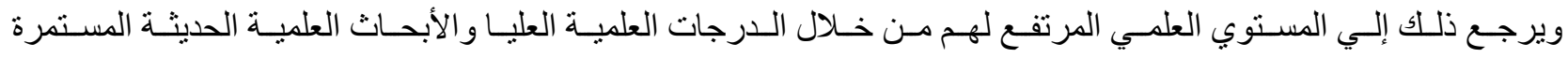

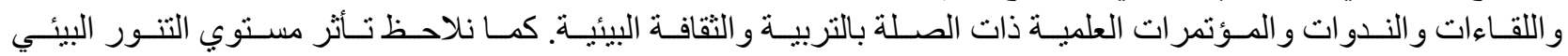

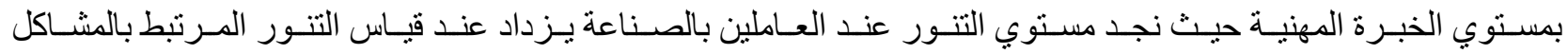

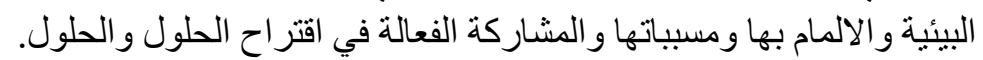

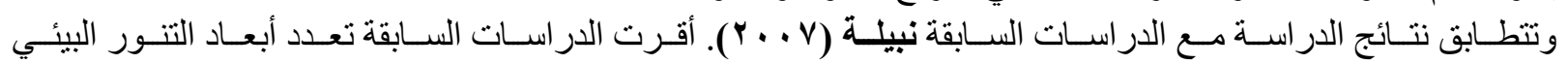

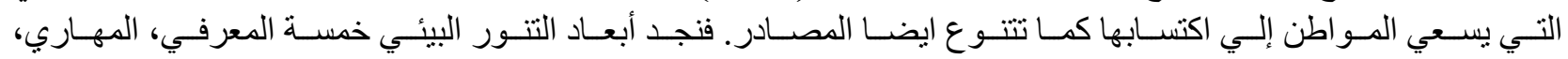

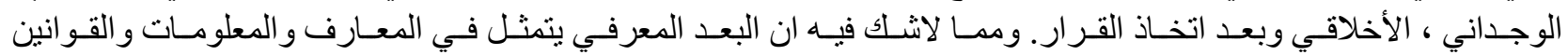

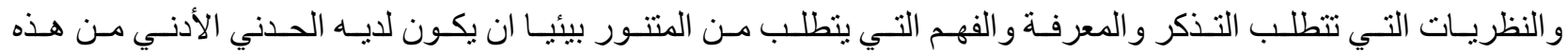

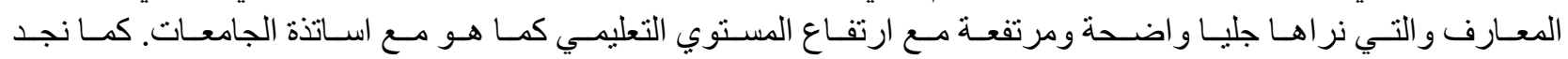

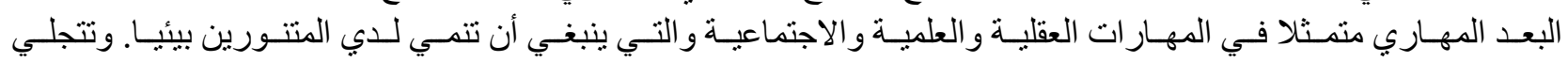

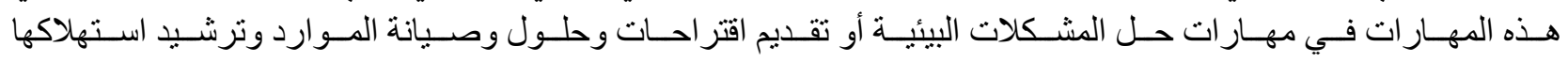

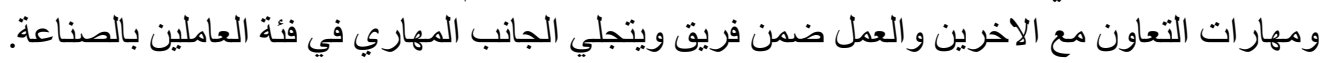

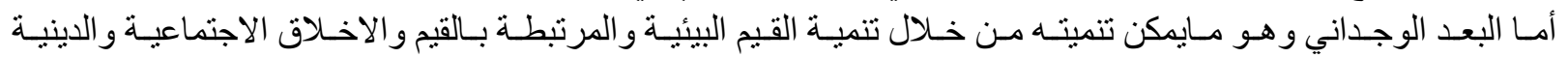

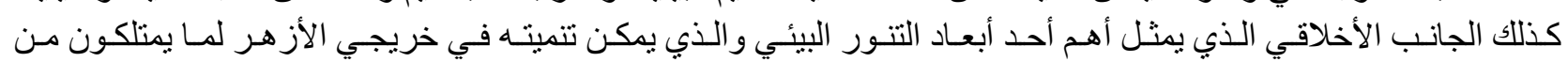

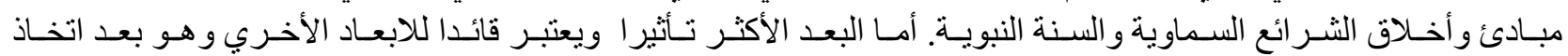

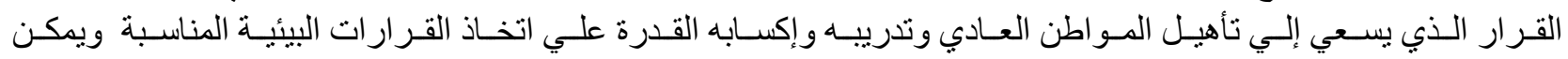

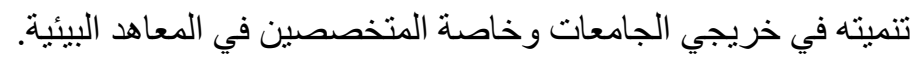




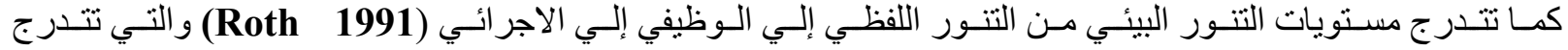

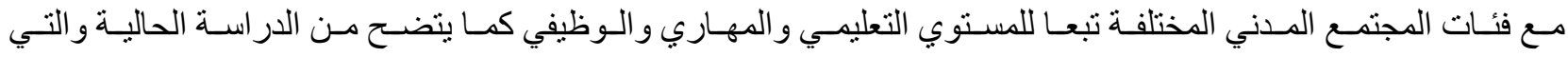

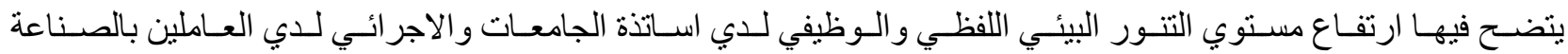

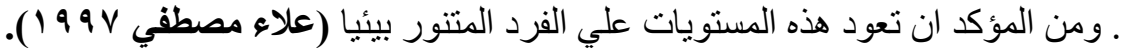

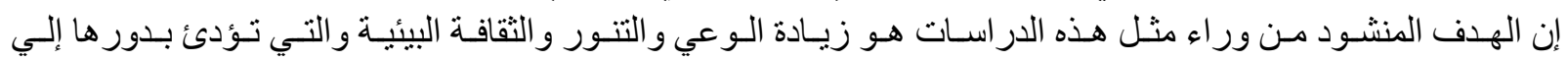

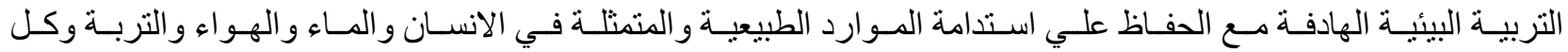

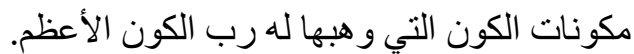

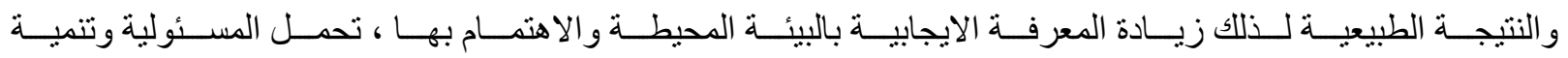
الاخلاقيات و الاتجاه الوجداني في المحافظة علي البيئة وجعل العادة عبادة في كل المعاملات البيئية المختلفة.

توصيات الاراسة

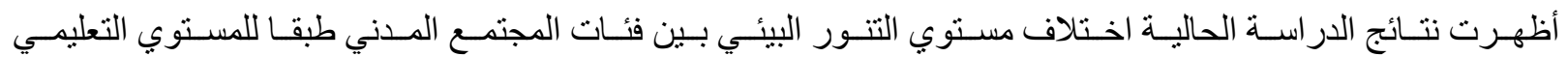

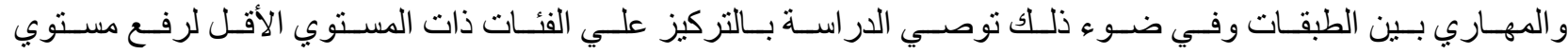

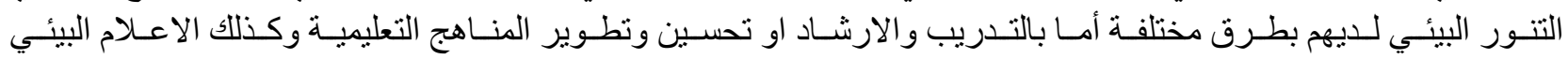
المباشر و الغير مباشر.

مقترحات الاراسة

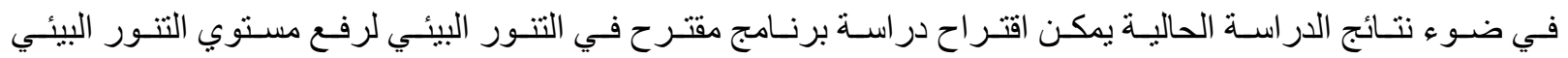

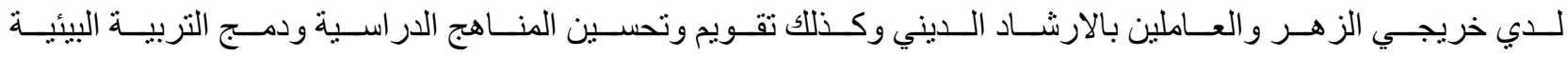
بالمقررات الدر اسية منفصلة أو مندمجة بما يعود علي الكون بالاستدامة و النفع لكل الأجبال.

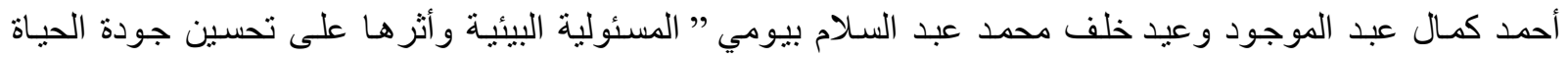

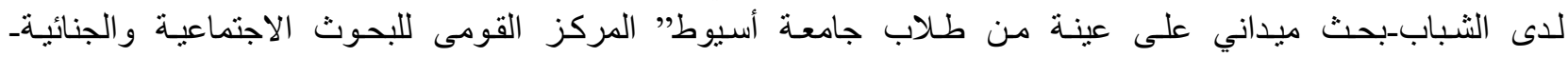

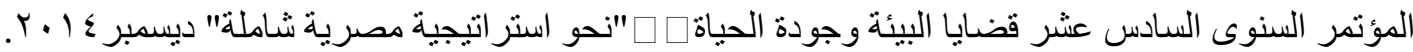

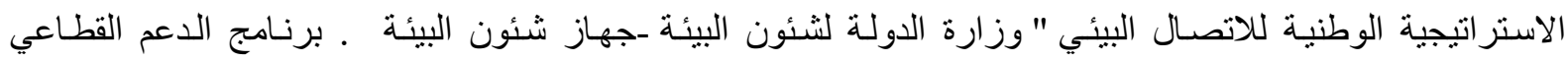

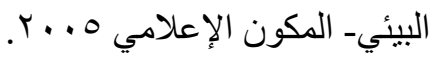

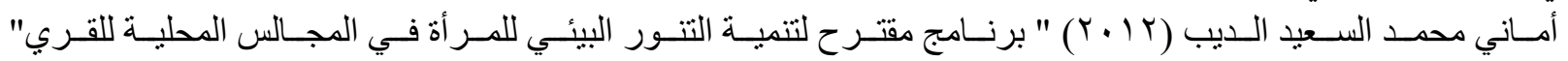

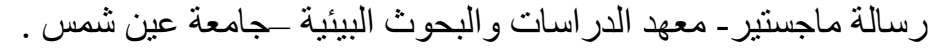

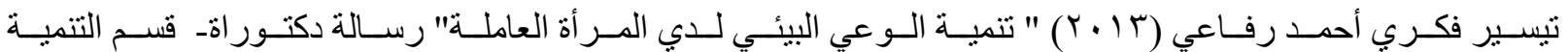

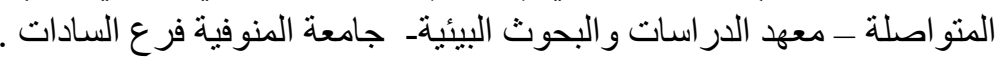

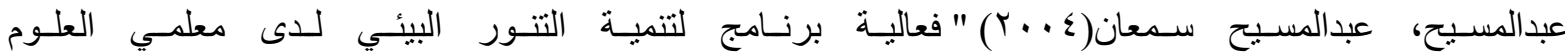

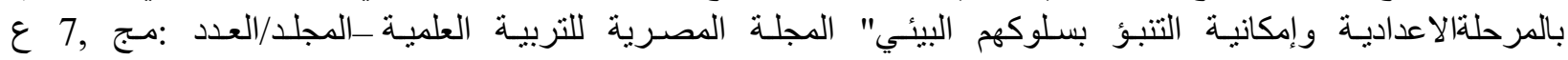
2167-197 الصفحات

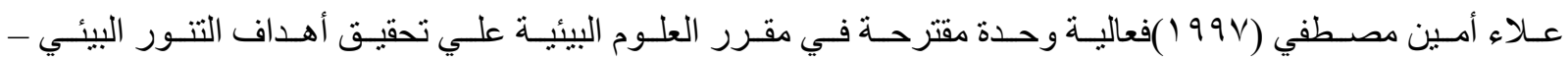
جامعة الفرعية -اليمن.

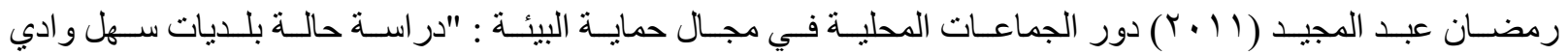

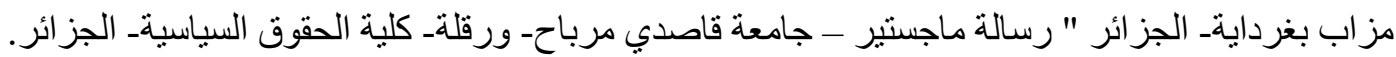

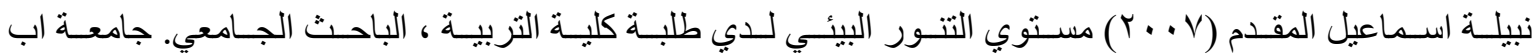

Danks, Sharon (1997): Environmental Literacy Course, University of California, San Diego.

Marcinkowski, Thomas, (1990) : An Environmental education approach to the training of the middle level teachers: A prototype program, Environmental Education 
series, No(30), UNES72) Roth, C (1991): Dose your Curriculum foster environmental literacy, San Francisco.

Shaique, Daudi (2000) : Exploring environmental literacy in communities of Pakistan, The Ohio state University.

Sherlock, Wallace (2003): Cross-cultural ecological literacy : A Rusian experiment with Antean Litrature, journal of Env, Edu, V (34)N, (2), PP 36-38.

\section{الملاحق}

نموذج لاستمارة استبيان

بعد التحية السبد / السيدة .

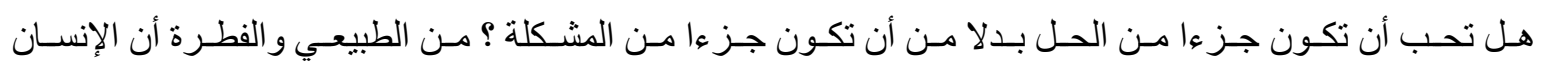

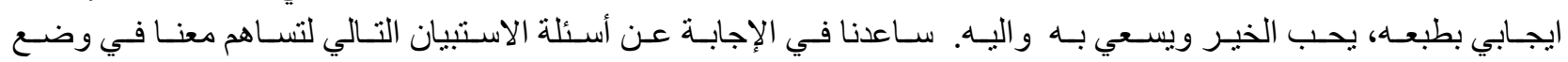

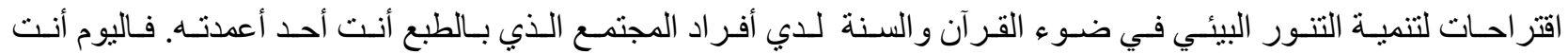

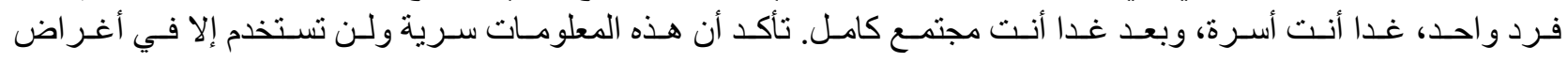

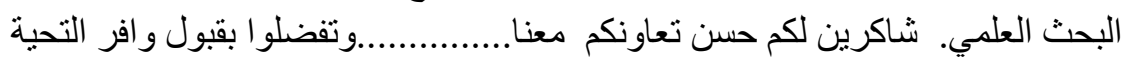

أ) كل ما يحيط بالانسان من كائنات حية و غير حية..(ب) كل ما يحيط من مؤثرات ثقافية واجتماعية

ج) جميع ما يحيط بالإنسان من ظروف و وعو امل تؤثر فيه ويؤثر فيها.

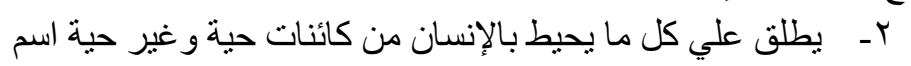

أ) البيئة البيولوجية (ب) البيئة الاجتماعية (ج) البيئة الطبيعية (د) البيئة الثقافية

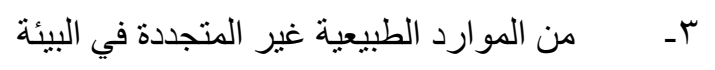

أ) الثرة الحيو انية (ب) الثروة المعدنية (ج) الثروة النباتية (د)الطاقة الثمسية

عـ - استخدام الطاقة الثمسية في تسخين المياه يؤدي إلي :

أ) قتل الميكروبات و الجر اثيم الموجودة في المياه (ب) تغير طعم ور ائحة الماء

ج) ترشيد استخدام الوقود الحفري (د) تقليل الجهد المبذول في استخدام الماء

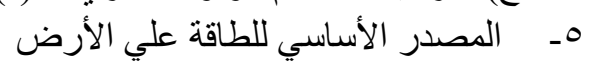

أ) الطاقة البترولية (ب) الطاقة الذرية (ج)الطاقة الثمسية (د)الطاقة الكيميائية

7- استخدام المياه الجوفية بكثرة لري الار اضي الصحر اوية المستصلحة يؤدي إلي:

أ) زيادة القدرة الانتاجية لهذه الأراضي (ب) سرعة نضوب الابار 


$$
\begin{aligned}
& \text { ج) حماية هذه الأر اضي من الانهيار (د)زيادة معدلات تماسك الطبقة السطحية لهذه الأر اضي }
\end{aligned}
$$

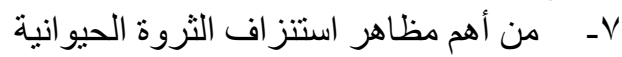

$$
\begin{aligned}
& \text { أ) انتشار الأمر اض المعدية بين الحيوانات (ب)استخدام الحيو انات في اعمال الزراعة والري } \\
& \text { ج) عدم استخدام النظام الغذائي المثالي (د)ذبح إناث المانشية الصغيرة السن }
\end{aligned}
$$

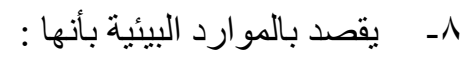

$$
\begin{aligned}
& \text { أ) ثروات طبيعية لا دخل للانسان فيها (ب) مو اد تتنجها الطبيعة و الانسان }
\end{aligned}
$$

ج)مركبـات ناتجــة عـن البنـاء الضــوئي للنباتـات (د)مركبـات يصـنـعها الانســان باسـتخدام الات وتكنولوجيـا مختلفة

9- من المصادر الدائمة للطاقة والتي لا يستطيع الانسان الاستغناء عنها

$$
\begin{aligned}
& \text { أ) البحار ب) الثمس ج) الفحم د) الأشجار } \\
& \text { • اـيتم الاستغلال الأمثل للثروة السمكية عن طريق: } \\
& \text { أ) صيد أكبر كمية منها لحل مشكلة البروتين الحيو اني } \\
& \text { ب) صيد الأنو اع المحببة للانسان وترك الأنواع الأخري }
\end{aligned}
$$

ت) صيد القدر المناسب منها بالصورة التي تضمن تكاثر ها واستمرارها ث) استخدام وسائل الصيد الحديثة للحصول علي أكبر كمية في وقت قصير ثانيا: التوازن البيئي:

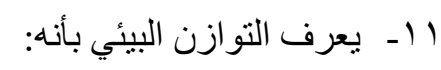

أ) الصر اع بين الكائنات الحية في البيئة وبقاء الأصلح منها ب) التساوي بين أعداد الكائنات الحية في البيئة

$$
\text { ج) التناسب بين أعداد الكائنات الحية والموارد المتاحة في البيئة }
$$

د) موت الأعداد الزائدة من الكائنات الحية عند نقص الغذاء في البيئة

$$
\text { r ا ـ للمحافظة علي التوازن البيئي بستلزم جميع ما يلي ما عدا: }
$$

أ) القضاء علي جميع الحشرات في البيئة المحيطة بنا ب) الاهتمام بزيادة المسطحات الخضراء

$$
\text { ج) جذخل الإنسان بصورة عقلانية في بيئته الاعتدال في استخدام المبيدات الحشرية. }
$$$$
\text { بـ إـ العلاقة الصحيحة بين الانسان و البيئة يمكن ان تكون علي النحو التالي: }
$$$$
\text { أ) البيئة هي المحدد للانشان ونشاطاته }
$$$$
\text { ب) الانسان هو سيد البيئة وله الحرية في فعل ما يشاء }
$$

ت) مر اعاة منطلبات الحياة الإنسانية ومنطلبات البيئة في الوقت نفسه

$$
\text { ث) تقليل معدلات التغيير في البيئة . }
$$




$$
\begin{aligned}
& \text { ع ا ـمن أهم مظاهر الاخلال بالثوازن البيئي في الوقت الراهن هي: } \\
& \text { أ) زيادة أعداد السكان (ب) استنز اف الموارد الطبيعية } \\
& \text { ج)تز ايد حدة مشكلات تلوث البيئة د)زت ايد اعتماد الانسان علي الآلات }
\end{aligned}
$$

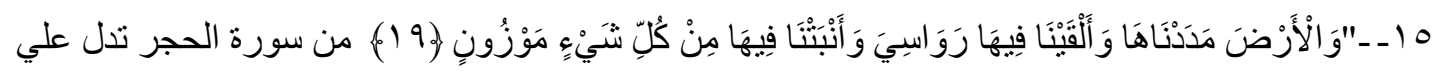

أ) مظاهر التوازن البيئي المتمثلة في مد الأرض، وتثبيتها بالجبال ،وكذا في النبات الموزون

$$
\text { ب) وصف الأرض وما مد بها من جبال فقط }
$$

ت) جيولوجية الأرض وما تحتوي . (ث) أن الجبال هي المثبتة للارض .

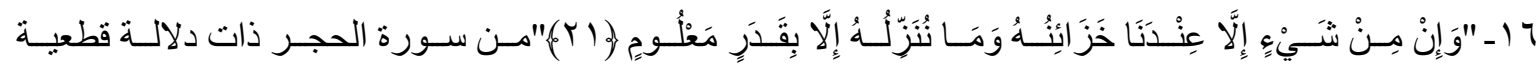

علي

أ) التوازن البيئي بكل جو انبه المكانية و الزمنية بما له من نفع واصلاح

ب) امتلاك الله للخز ائن وقدرته علي المنع و العطاء

ت) تسخير الله سبحانه وتعالي للطبيعة (ث) قدرة الله علي حفظ السلالات

I ا انفلونز ا الخنازير شجعت علي استباحة ذبحها في أماكن كثيرة مما أدي إلي

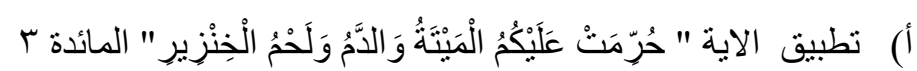

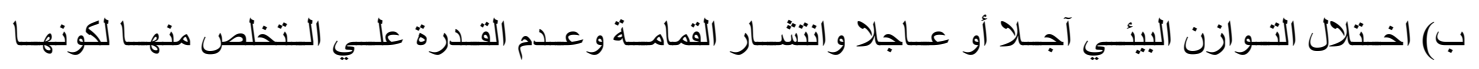
طعامه الأساسي الخي الخي

ت) التخلص من حيو ان قبيح المنظر

ث) الحفاظ علي التوازن البيولوجي بالقضاء علي وباء الانفلونز ا

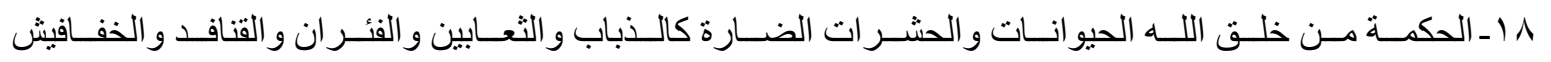
و العقارب هي

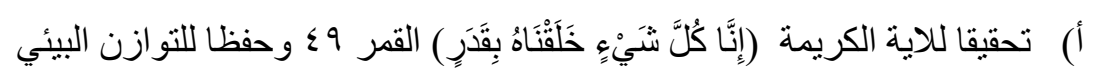
ب) لمعاقبة المخطئين و المذنبين (ث)لجعلها آيات و عبر للمو عظة ت) للتعايش فيما بينها دون ضرر

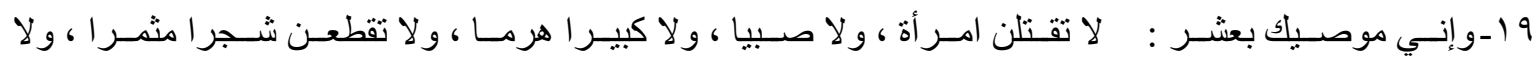

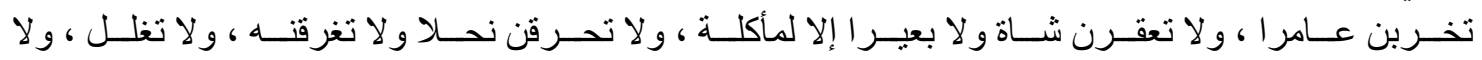

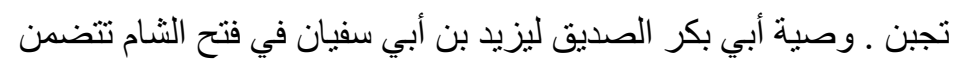
أ) الحفاظ علي الثروات الطبيعية حتي في حالة الحرب تأكيد للتوازن البيئي ب) وصية للحفاظ علي النساء فقط (ت) للحفاظ علي الثروة الحيو انية فقط ت) لحفظ اتز ان النباتات لغذاء الانسان و الحيوان 


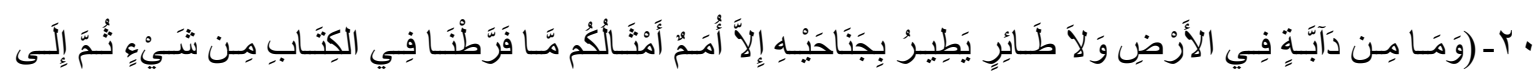

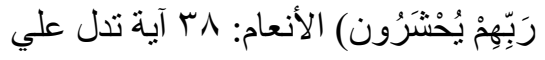
أ) القدرة الالهية علي حفظ سلالات الكائنات الحية (ب)يوم الحشر وتبعاته ج)كيفية طير ان الطيور (د)وصية للانسان للمحافظة علي الدواب ثالثا: المشكلات البيئية :ا ا ـ انتشار التوسع العمر اني في المناطق الصحر اوية البكر يدل علي أ) التوجيه الصحيح لحل مشكلة الاسكان ب) انها من الاسباب الرئيسية للتصحر ت) عدم التوجيه السليم لاستغلال الأرض كمورد طبيعي ث) التنمية المستدامة Y Y Y - من الأسباب الرئيسية للسحابة السوداء طو ال العام أ) حرق المخلفات الزر اعبة كقش الأرز ب) حرق أكوام القمامة بصورة عشو ائية ت) عوادم السيارات في الأماكن المزدحمة ث) (أ)و (ب) و (ت ) معا. ب ـ حل الشكلات البيئية يحتاج إلي: أ) الالمام بعلوم الأحياء ب) الالمام التام بجميع العلوم الطبيعية ت) الالمام التام بالعلوم الاجتماعية ث) تعاون جميع المجالات المعرفية ـ זـ التلوث البيئي هو عبارة عن تغير: أ) كيفي يطرأ علي احد مكونات البيئة ويؤدي لتغيير مر غوب فيه ب) كمي بطر أ علي احد مكونات البيئة ويؤدي لتغير مرغوب فيه ت) كمي وكيفي يلحق بأحد مكونات البيئة ويخل بنوازنها ث) كمي وكيفي يلحق بأحد مكونات البيئة ويؤدي لاستقرار النظام البيئ هץ الأمطار الحمضية تنتج عن تلوث الهواء الجوي بغاز :

أ) الأكسجين ب) بخار الماء ج) النيتروجين د) ثاني اكسيد الكبريت 


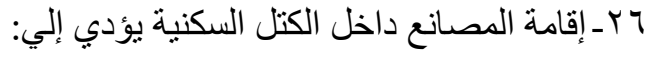

أ) توفير في استهلاك الطاقة

ب) (ختلال التوازن البيئي

ت) توفير فرص عمل مناسبة للمو اطنين

ث) المساهمة في حل مشكلة المو اصلات

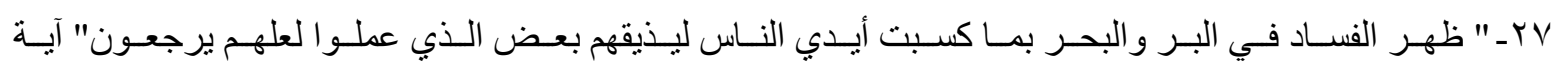
قر آنية تتضمن:

أ) لنتائج التلوث البيئي السلبية علي الانسان وردعه للرجوع إلي الصحيح

ب) دعوة للتوبة و البعد عن المعاصي

ت) دعوة للارجوع إلي الله

ث) أهور الفساد المطلق

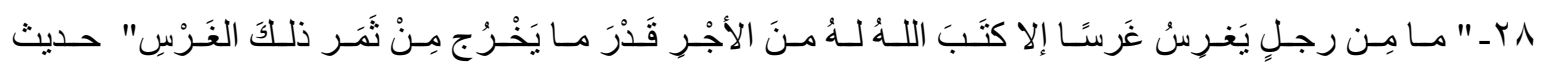

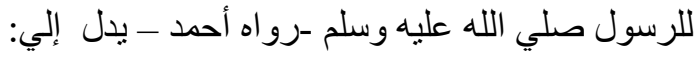

أ) كثرة الغرس و التشجير لكل الناس

ب) لفظ رجل في هذه الرواية دعوة للانسانية جمعاء للتشجير و الزر اعة

ت) تنفيذ هذا الحديث يقضي علي ظاهرة الاحتباس الحراري

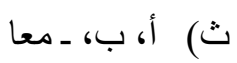

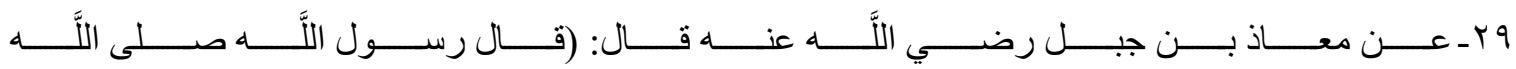

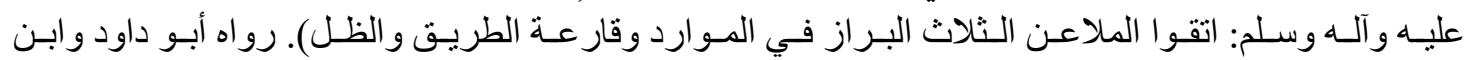

ماجه - هذا الحديث

أ) يحافظ علي الثروة المائية بكل مكوناتها

ب) يرفض الصرف الصحي و الصناعي علي موارد الماء

ت) يصون الموارد الطبيعية _الماءـ الأرض و الثجر من الفساد

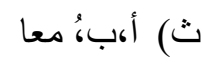

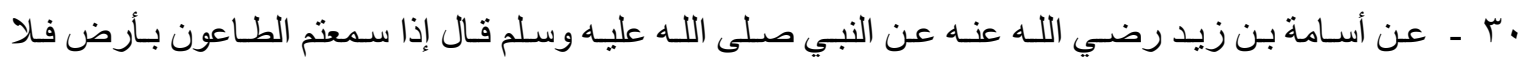

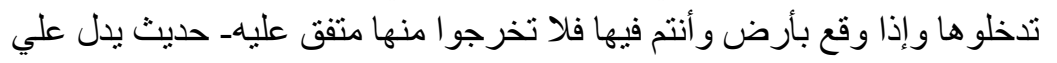

أ) جواز الحجر الصحي ب) عدم مخالطة الاصحاء المرضي

ج) عر اهة النزول بأرض بها بلاء د)تحريم التلوث البيولوجي للهو اء 